\title{
"FUTURO DO PRETÉRITO": BIM E DOCUMENTAÇÃO DIGITAL DA ARQUITETURA MODERNA EM FORTALEZA 1
}

\author{
"FUTURE IN THE PAST": BIM AND DIGITAL DOCUMENTATION OF \\ MODERN ARCHITECTURE IN FORTALEZA
}

\author{
Ricardo Alexandre Paiva \\ Universidade Federal do Ceará (UFC) \\ paiva ricardo@yahoo.com.br \\ Beatriz Helena Nogueira Diógenes \\ Universidade Federal do Ceará (UFC) \\ bhdiógenes@yahoo.com.br \\ Daniel Ribeiro Cardoso \\ Universidade Federal do Ceará (UFC) \\ daniel.br@mac.br
}

\begin{abstract}
Resumo
Atualmente, as novas tecnologias digitais constituem relevantes instrumentos não só da concepção, desenvolvimento do projeto, geração e gestão da informação, mas desempenham também importante papel como ferramenta para documentação, intervenção e conservação do patrimônio arquitetônico (moderno ou não). Neste sentido, o objetivo do trabalho é discutir teórica e empiricamente a interface entre a tecnologia BIM e a documentação da arquitetura moderna em Fortaleza. O trabalho integra uma pesquisa mais ampla financiada pelo CNPq denominada "(Re)construção da Arquitetura Moderna em Fortaleza: memória e modelagem digital" e compõe uma das atividades de investigação do Laboratório de Crítica em Arquitetura, Urbanismo e Urbanização (LoCAU) e do Laboratório de Experiências Digitais (LED) do Programa de Pós-Graduação em Arquitetura e Urbanismo e Design da UFC (PPGAU+D-UFC). Os métodos utilizados compreendem inicialmente, a ampliação da revisão bibliográfica, tanto em relação ao referencial teórico sobre a arquitetura moderna em Fortaleza, como em relação ao uso das tecnologias digitais no campo da arquitetura e como ferramenta de documentação e sua interface com o design da informação. Para respaldar os procedimentos práticos da pesquisa será apresentado o processo de modelagem, sistematização e inventário, constando a simulação digital de uma obra moderna de Fortaleza (Pavilhão Martins Filho).
\end{abstract}

Palavras-chave: BIM. documentação digital. arquitetura moderna. Fortaleza

\begin{abstract}
Currently, the new digital technologies are relevant instruments not only of design, project development, generation and management of information, but also play an important role as a tool for documentation, intervention and conservation of architectural heritage (modern or not). In this sense, the goal of the paper is to discuss theoretically and empirically the interface between BIM and the documentation of modern architecture in Fortaleza. The work is part of a broader research financed by $\mathrm{CNPq}$ called "(Re) Construction of Modern Architecture in Fortaleza: memory and digital modeling" and it is part of the research activities of Critical Laboratory of Architecture, Urbanism and Urbanization (LoCAU) and Laboratory Digital Experiences (LED) of the Graduate Program in Architecture and Urban Planning and Design of the UFC (PPGAU + D-UFC). The methods
\end{abstract}

\footnotetext{
${ }^{1}$ PAIVA, Ricardo; DIÓGENES, Beatriz; CARDOSO, Daniel. "Futuro do Pretérito": BIM e Documentação Digital da Arquitetura Moderna em Fortaleza. In: ENCONTRO BRASILEIRO DE TECNOLOGIA DE INFORMAÇÃO E COMUNICAÇÃO NA CONSTRUÇÃO, 7., 2015, Recife. Anais... Porto Alegre: ANTAC, 2015.
} 
used include initially, expanding the literature review, both the theoretical framework of modern architecture in Fortaleza, such as the use of digital technologies in the field of architecture and as documentation tool and its interface with the design information. To support the practical procedures of the research will be presented the modeling process, organization and inventory, showing the digital simulation of a modern work of Fortaleza (Martins Filho Pavilion).

Keywords: BIM. digital documentation. modern architecture. Fortaleza-Ceará-Brazil

\section{INTRODUÇÃO}

A documentação da arquitetura moderna constitui uma importante premissa para sua valorização e consequente conservação. É lamentável constatar que muitas das obras modernistas de Fortaleza já não existem mais ou foram descaracterizadas e que a precária sistematização da documentação sobre essa produção dificulta a compreensão de seu valor, tanto para o estudo da arquitetura cearense, como para a sua preservação. Atualmente, as novas tecnologias digitais constituem relevantes instrumentos não só da concepção, desenvolvimento do projeto, geração e gestão da informação, mas desempenham também importante papel como ferramenta para documentação e intervenção no patrimônio arquitetônico (moderno ou não).

Neste sentido, o objetivo do trabalho é discutir teórica e empiricamente a interface entre a tecnologia BIM e a documentação da arquitetura moderna em Fortaleza. O trabalho integra uma pesquisa mais ampla financiada pelo Conselho Nacional de Desenvolvimento Científico e Tecnológico (CNPq) denominada "(Re)construção da Arquitetura Moderna em Fortaleza: memória e modelagem digital" e compõe uma das atividades de investigação do Laboratório de Crítica em Arquitetura, Urbanismo e Urbanização (LoCAU) e do Laboratório de Experiências Digitais (LED) do Programa de Pós-Graduação em Arquitetura e Urbanismo e Design da UFC.

Os métodos utilizados compreendem inicialmente a ampliação da revisão bibliográfica, tanto em relação ao referencial teórico sobre a arquitetura moderna em Fortaleza, como em relação ao uso das tecnologias digitais no campo da arquitetura e como ferramenta de documentação e sua interface com o design da informação. Para respaldar os procedimentos práticos da pesquisa será apresentado o processo de modelagem, sistematização e inventário, constando da simulação digital de uma obra moderna de Fortaleza (Pavilhão Martins Filho, do Departamento de Arquitetura e Urbanismo da UFC), com base nas pesquisas em andamento.

Estes pressupostos teórico-práticos qualificam positivamente o trabalho como uma contribuição para a documentação digital da arquitetura. A produção da documentação digital da arquitetura moderna em Fortaleza por intermédio da tecnologia BIM evidenciará os estudos realizados e em andamento no âmbito do Programa de Pós Graduação em Arquitetura e Urbanismo e Design da Universidade Federal do Ceará (PPGAU+D-UFC), subsidiando as pesquisas locais, possibilitando a divulgação dos seus resultados, suscitando o aprofundamento de alguns temas e abrindo fóruns de debates sobre o papel das tecnologia (futuro) na documentação, valorização, preservação e conservação do patrimônio moderno (pretérito).

\section{BIM E DOCUMENTAÇÃO DIGITAL}

A produção da documentação digital das obras modernistas em Fortaleza constitui, pois, importante contribuição para a historiografia da arquitetura regional, sendo um instrumento de preservação da memória deste patrimônio arquitetônico que, embora tenha sido 
produzido em um passado recente, apresenta muitos exemplares já demolidos ou em estágio avançado de degradação. A (re)construção virtual da deste acervo através da modelagem digital dos edifícios emblemáticos se apresenta, portanto, como uma possibilidade de prolongar a sua existência, seja pelo resgate da memória dos edifícios demolidos, através de uma espécie de "ressuscitação", seja pela valorização do acervo remanescente.

O advento das novas tecnologias digitais e seus impactos na área de Arquitetura, Engenharia, Construção e Operação (AECO) têm contribuído sobremaneira para a disseminação de conhecimento e desempenhado um papel relevante como instrumento não só da concepção, desenvolvimento do projeto, geração e gestão da informação, mas da materialização e inovações de grande valia para a documentação e inclusive intervenção no patrimônio arquitetônico e urbanístico. Dentre as diversas tecnologias, destacam-se as Realidade Virtual, Realidade Misturada e/ou Aumentada, Tecnologias Web, SIG, CAD, BIM, HBIM, Prototipagem Rápida e Fabricação Digital, entre outros.

Lima (2014) sintetiza as principais tecnologias digitais a serviço da documentação e conservação do patrimônio arquitetônico (moderno ou não).

Quadro 1 - Operações digitais que podem ser utilizadas na conservação do patrimônio e suas principais características.

\begin{tabular}{|c|c|}
\hline $\begin{array}{l}\text { representação } \\
\text { técnica }\end{array}$ & $\begin{array}{l}\text { - uso de CAD no desenho técnico, elaboração de projeções planas, melhorando a } \\
\text { características gráficas, a execução precisa e rápida, o automatismo de diversas } \\
\text { exigências técnicas, a produção de múltiplas cópias, etc. }\end{array}$ \\
\hline $\begin{array}{l}\text { modelagem } \\
\text { tridimensional }\end{array}$ & $\begin{array}{l}\text { - softwares para representação tridimensional, visualização sob inúmeros pontos de } \\
\text { vista, simulação visual de características, recursos técnicos de desempenho e também a } \\
\text { inclusão de novas características entre aplicativos diferentes. }\end{array}$ \\
\hline $\begin{array}{c}\text { modelagem } \\
\text { paramétrica / BIM }\end{array}$ & $\begin{array}{l}\text { - programas gráficos baseados em parâmetros e hierarquias, desenvolvimento de } \\
\text { segmentos específicos constituídos por variações válidas, componentes, conexões e } \\
\text { agrupamentos. Além disso, a representação digital do processo de construção para } \\
\text { facilitar o intercâmbio e a interoperabilidade da informação no formato digital. }\end{array}$ \\
\hline $\begin{array}{l}\text { recursos } \\
\text { generativos e de } \\
\text { performance }\end{array}$ & $\begin{array}{l}\text { - softwares com recursos de algoritmos randômicos, evolutivos, etc. Também processos } \\
\text { capazes de modelar as geometrias segundo simulação de melhor desempenho de } \\
\text { conforto térmico, acústico, lumínico, etc. }\end{array}$ \\
\hline fabricação digital & $\begin{array}{l}\text { - ferramentas de fabricação computadorizada, recursos de corte laser, fresadoras para } \\
\text { desbaste tridimensional, impressoras laser, equipamentos de técnicas formativas tais } \\
\text { como dobragem, prensa, moldagem a vácuo, térmica, etc. }\end{array}$ \\
\hline escaneamento 3D & $\begin{array}{l}\text { - varredura de dados 3D, captura de modelos realizados fisicamente e que podem sofrer } \\
\text { processos digitais, aplicação de novas camadas de ajustes ou mesmo impressão em } \\
\text { novos materiais. }\end{array}$ \\
\hline $\begin{array}{l}\text { ambiente virtual } \\
\text { imersivo }\end{array}$ & $\begin{array}{l}\text { - ambientes virtuais acessados por capacetes, luvas, na interação com cenários que } \\
\text { permitem um espaço interativo, lidando com o corpo e as percepções das relações } \\
\text { espaciais de modo sinestésico. }\end{array}$ \\
\hline
\end{tabular}

Fonte: LIMA, 2015, p. 116

Dentre estas tecnologias, destacam-se os modelos geométricos tridimensionais, que representam uma poderosa forma de registro, pois permitem a visualização dos objetos em diversas escalas e níveis de detalhamento, podendo ser usados em programas de "renderização", simulação, animação e realidade virtual (AMORIM et al, 2008:202).

O uso do BIM (Building Information Modeling) como tecnologia que lança mão de modelos paramétricos para fins de documentação e intervenção no patrimônio modernista permite, além da sua (re)construção por intermédio da simulação virtual, a exploração e a gestão da informação, transformando-se em objeto e fonte de estudo, com desdobramentos em diversas atividades de ensino (graduação e pós-graduação), pesquisa e extensão. O BIM constitui:

Um paradigma avançado de trabalho colaborativo, que usa um modelo criado a partir de informações coordenadas e consistentes. Enquanto as 
ferramentas CAD focam apenas o projeto e a representação da edificação, a modelagem da informação da construção (conforme a tradução de BIM adotada pela ABNT) pretende dar conta de todo o ciclo de vida da edificação, e este é um aspecto que se presta muito bem ao patrimônio arquitetônico na medida em que permite cadastra-lo, estuda-lo, modifica-lo e mantê-lo para as futuras gerações. Além disto, o BIM possui outras excelentes características, tais como: visualização 3D e animações, a automação da produção de documentos (projeções ortográficas, cortes, seções, detalhes, relatórios, listagens, etc.), simulações de desempenho estrutural, energético, ambiental, e de custos. Os objetos paramétricos (tais como janelas, portas, paredes, telhados, etc.) não são definidos isoladamente, mas como parte de sistemas que mantem relação e interação com os outros objetos (TOLENTINO e FEITOSA, 2015, p. 307)

Descendente do BIM, o Historic Building Information Modeling (HBIM) tem função específica direcionada para a documentação, análise e conservação. Trata-se de um processo de engenharia reversa que, por intermédio do mapeamento dos elementos arquitetônicos, utiliza o recurso de um laser scanner ou fotogrametria. De modo geral, o HBIM tem sido usado mais para a documentação de edifícios antigos do que para os modernos, talvez por funcionar como recurso bastante adequado de escaneamento de elementos ornamentais e detalhes construtivos.

A modelagem paramétrica presente no BIM possibilita a simulação de intervenções no edifício que pode redundar em soluções mais criteriosas de conservação, passíveis de serem testadas e visualizadas por intermédio das informações e interfaces que o BIM disponibiliza. Os atributos de "multidisciplinaridade" e "interoperabilidade" (ANDRADE e RUSCHEL, 2011) presentes nos processos do BIM para a concepção, construção e manutenção de edifícios podem ser transferidos e ampliados para a documentação e conservação de edifícios históricos.

Esta interface entre documentação, modelagem digital e também projeto constituem objetos de estudos emergentes no campo disciplinar da arquitetura e urbanismo. Destacam-se as experiências do banco de dados do "habitar moderno e habitar contemporâneo", coordenado pelos professores Marcio Cotrim, Wylnna Vidal e Nelci Tinem, vinculado às pesquisas do PPGAU/UFPB, que por sua vez está articulado à pesquisa Història en Obres divulgada no Portal/Revista de História da Arquitetura Moderna, coordenado pelo professor Fernando Alvarez Prozorovich (ETSAB/UPC). No âmbito nacional vale ressaltar ainda: o Grupo de pesquisa "A construção formal na arquitetura", coordenado pelo Prof. Edson Mahfuz vinculado ao PROPAR/UFRGS; e o LCAD - Laboratório de Computação Gráfica Aplicada à Arquitetura e ao Desenho, sob a liderança do Professor Arivaldo Amorim da FAU-UFBA.

\section{A DOCUMENTAÇÃO DA ARQUITETURA MODERNA EM FORTALEZA}

A documentação da arquitetura moderna em Fortaleza tem sido objeto de estudo de alguns pesquisadores locais. Estas pesquisas têm redundado em dissertações de mestrado, teses de doutorado e diversos trabalhos apresentados em anais de eventos e periódicos, enfocando a contribuição de diversos arquitetos à arquitetura moderna em Fortaleza, além da contribuição das suas atividades profissionais, de ensino e a obra construída. A divulgação dos resultados tem sido apresentada sistematicamente nos Seminários de Documentação e Conservação do Movimento Moderno (DOCOMOMO), nas suas edições nacional e regional (N/NE), e em outros eventos que tratam da questão da documentação e preservação da arquitetura e em revistas científicas especializadas. Os Seminários do DOCOMOMO se transformaram no principal espaço de trocas sobre a documentação e preservação da arquitetura moderna no Brasil, sublinhando sobremaneira a diversidade 
desta produção e sua aclimatação nas diversas regiões do país, colocando em evidência suas especificidades.

Outro esforço de documentação, digno de ser citado, foi a produção do Inventário da Arquitetura Moderna em Fortaleza, iniciativa que surgiu da parceria entre o Laboratório de Estudos em Arquitetura e Urbanismo (LEAU), do Departamento de Arquitetura e Urbanismo (DAU) da Universidade Federal do Ceará (UFC) e $4^{\text {a }}$. Superintendência Regional do Instituto do Patrimônio Histórico e Artístico Nacional (IPHAN). A pesquisa foi liderada pelo Prof. Dr. Clovis Ramiro Jucá Neto e redundou em um importante acervo iconográfico da produção da arquitetura moderna em Fortaleza.

Os estudos sistemáticos desenvolvidos e publicados pelos professores/pesquisadores do DAU-UFC propiciaram a visibilidade da produção de conhecimento sobre a arquitetura moderna em Fortaleza. Neste contexto, e por estar comprometido com a necessidade de documentação e conservação do patrimônio moderno no Nordeste, o DAU-UFC organizou a quinta edição do Seminário DOCOMOMO N/NE, que aconteceu em novembro de 2014.

O esforço de sistematização e síntese das pesquisas já realizadas e ampliação da documentação do acervo da arquitetura modernista local redundou no desenvolvimento de um projeto de pesquisa intitulado "Guia da Arquitetura Moderna em Fortaleza (1960-1982)" contemplado com Auxílio Financeiro do Programa Jovens Pesquisadores PJP Edital 07/2012 da FUNCAP (Fundação Cearense de Apoio ao Desenvolvimento Científico e Tecnológico). A atividade compõe as ações do LoCAU (Laboratório de crítica em Arquitetura, Urbanismo e Urbanização) do Departamento de Arquitetura e Urbanismo da Universidade Federal do Ceará (UFC) que tem como objetivo a realização de estudos e pesquisas sobre a produção e o consumo do espaço na contemporaneidade à luz de uma perspectiva crítica e histórica das manifestações socioespaciais da arquitetura, do urbanismo e da urbanização.

Os guias de arquitetura são instrumentos instrutivos que orientam pesquisadores e visitantes sobre aspectos fundamentais da produção da arquitetura de um determinado lugar, ao oferecer condições mínimas de conhecimento do patrimônio edificado e proporcionar possibilidades distintas de informação e interpretação da obra, assim como sua inserção espacial e temporal.

O suporte teórico da pesquisa do Guia foi estruturado em duas vertentes conceituais:

- a primeira se concentrou na produção bibliográfica nacional sobre a arquitetura moderna, que enfatiza os desdobramentos do movimento nos principais centros regionais, inclusive no Nordeste.

- a segunda se debruçou sobre a produção historiográfica local, que embora não esteja consolidada, revela as especificidades do modernismo arquitetônico no Ceará e sobretudo em Fortaleza.

A obtenção das fontes primárias constituiu outro procedimento metodológico (já finalizado) e se estruturou basicamente de duas formas. A primeira relacionada à análise de documentos, desenhos, plantas, projetos, entre outros, de acervos pessoais e públicos das obras mais emblemáticas; a segunda baseada na História Oral, na medida em que a trajetória e o depoimento destes arquitetos (na sua maioria ainda vivos) constituem ao mesmo tempo, fonte e objeto de documentação do desenvolvimento da diversidade da arquitetura moderna nos centros regionais.

A partir da construção deste aparato - pressupostos teóricos e práticos - foi elaborada uma seleção das obras mais representativas, divididas com base na tipologia dos edifícios e uma ficha de caracterização da obra contando informações e iconografia. 
Embora a produção do Guia seja importante instrumento de documentação, a continuidade da sistematização deste acervo já iniciado constitui importante objeto de estudo, verticalizando as pretensões e o alcance das pesquisas desenvolvidas.

A produção da documentação digital destas obras constitui importante contribuição para historiografia da arquitetura regional, sendo um instrumento de preservação da memória deste patrimônio arquitetônico, que embora sejam de um passado recente, apresenta muitos exemplares já demolidos ou em estágio avançado de degradação. A (re)construção virtual da arquitetura moderna em Fortaleza através da modelagem digital dos edifícios emblemáticos se apresenta como uma possibilidade de prolongar a sua existência, seja pelo resgate da memória dos edifícios demolidos, através de uma espécie de ressuscitação, seja pela valorização do acervo remanescente.

A documentação deste acervo tem sido construída também através de levantamentos, que são digitalizados e fornecem as bases para a modelagem paramétrica das obras. Os modelos são construídos considerando a sua lógica estrutural, atentando para modulações, tramas e padrões; o conjunto das vedações, distinguindo alvenarias e esquadrias; e finalmente são modelados os elementos da coberta. Estas camadas possibilitam a visualização compartimentada, contribuindo sobremaneira para a compreensão da concepção e construção do edifício em questão.

\section{O PAVILHÃO MARTINS FILHO EM FORTALEZA}

O processo de documentação digital por intermédio do BIM nasceu da articulação das atividades do LoCAU, do LED e das atividades das disciplinas de desenho assistido por computador da graduação do Curso de Arquitetura e Urbanismo da UFC.

Inicia-se em 2009 a crítica e a revisão do conteúdo dos programas das disciplinas da Linha Percepção e Representação do Curso de Arquitetura e Urbanismo do DAU-UFC. O esforço coadunava com o propósito da criação de um novo Projeto Político Pedagógico mais coerente com as demandas atuais da sociedade. À época, especificamente a disciplina de Desenho Arquitetônico II (DA-II), então ofertada para alunos do $7^{\circ}$ semestre, trazia em seu programa "os sistemas operacionais e os equipamentos para CAD". Tradicionalmente o ensino traduzia-se no ensino do aplicativo de desenho vetorial em $2 D$ e $3 D$ - AutoCAD da Autodesk. A partir de 2011, como resultado da revisão, insere-se ao programa de DA-II o tema BIM acrescentando ao programa diretrizes mais gerais como "iniciar o estudante de arquitetura e urbanismo nos processos de Modelagem da Informação na Construção (BIM)". Com a efetiva implantação do novo PPP em 2012, o conteúdo da disciplina passa a fazer parte do $3^{\circ}$ semestre com a criação da disciplina de Desenho Arquitetônico Auxiliado por Computador (DAAC). O conteúdo programático sugerido consiste:

- Unidade 1 (12h) Conceitos e estudos de caso, com a realização de seminário;

- Unidade 2 (36h) - Aplicativos BIM, com atividades de modelagem em Archicad (Graphisoft);

- Unidade $3(16 \mathrm{~h})$ - Concepção e modelagem de edifício proposto para disciplinas de Projeto Arquitetônico.

Atualmente, como parte das atividades ligadas à Unidade 2 da disciplina, tem-se sugerido a modelagem de projetos modernistas compilados no Guia. Como um dos exemplos, apresenta-se o Pavilhão Reitor Martins Filho. Projeto de autoria da arquiteta Nícia Paes Bormann, realizado em 1966-67 no pátio do DAU-UFC, o Pavilhão Reitor Martins Filho possui dois pavimentos (um térreo e um mezanino). "Originalmente, o programa do pavimento térreo era composto por três partes espacialmente bem definidas" (JUCÁ NETO et al, 2014). O edifício expressa valores notadamente modernistas, visíveis na racionalidade 

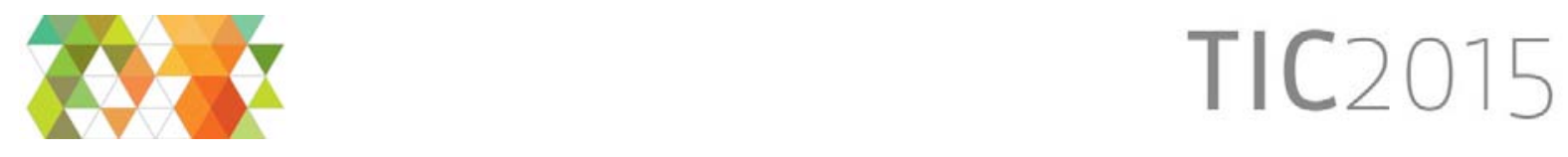

construtiva e na divisão explícita entre os elementos estruturais (concreto e metálica) e a vedação (venezianas de madeira e vidro). Ao mesmo tempo que apresenta elementos industrializados, o edifício revela traços de trabalho artesanal, sobretudo nos componentes em madeira (Figura 1).

Figura 1 - Foto Antiga Pavilhão Martins Filho

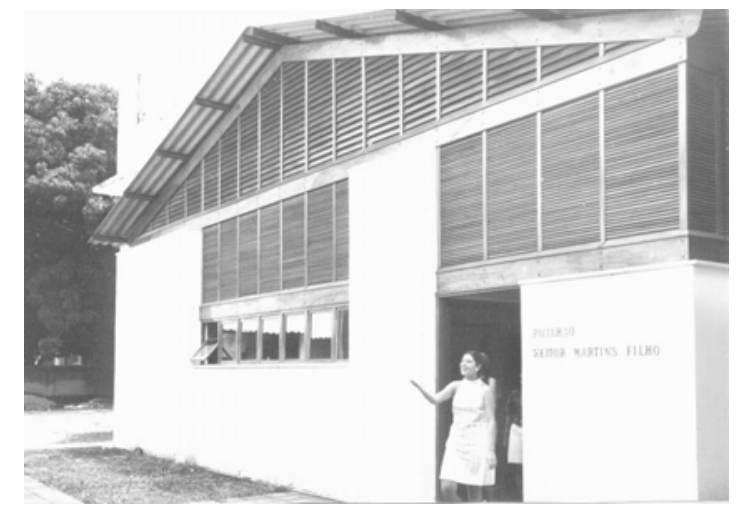

Fonte: Museu de Arte da Universidade Federal do Ceará (MAUC)

Atualmente, por ocasião da implantação do Curso de Design, o pavilhão passou por uma reforma para acomodar a Oficina Digital, o Atelier Digital e salas do PPGAU+D (Figura 2). O projeto de adequação da edificação às novas demandas programáticas foi concebido se valendo do BIM e possibilitou a simulação das soluções de intervenção, respeitando os seus valores modernos intrínsecos e contribuindo para a sua conservação e uso.

Figura 2 - Foto Antiga Pavilhão Martins Filho

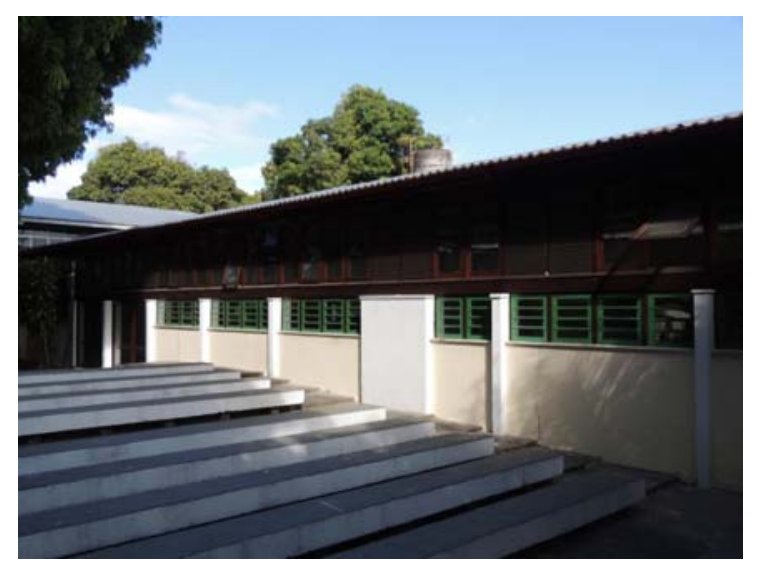

Fonte: Acervo Ricardo Paiva

O Pavilhão Martins Filho foi objeto de modelagem na disciplina de DAAC nos semestres 2014-2 e 2015-1. As imagens advindas da realização do trabalho demonstram a relevância da documentação digital no processo de documentação e conservação da arquitetura moderna em Fortaleza (Figuras 3, 4, 5 e 6). 
Figura 3 - Planta Térreo e Superior Pavilhão Martins Filho.

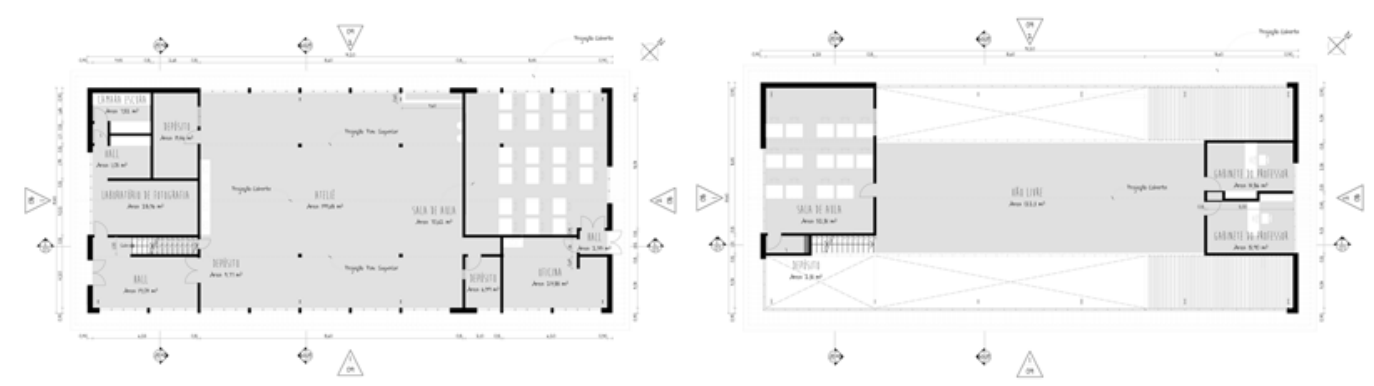

Fonte: Modelo desenvolvido na disciplina DAAC. Autora Karine Rabelo

Figura 4 - Perspectivas do Pavilhão Martins Filho.
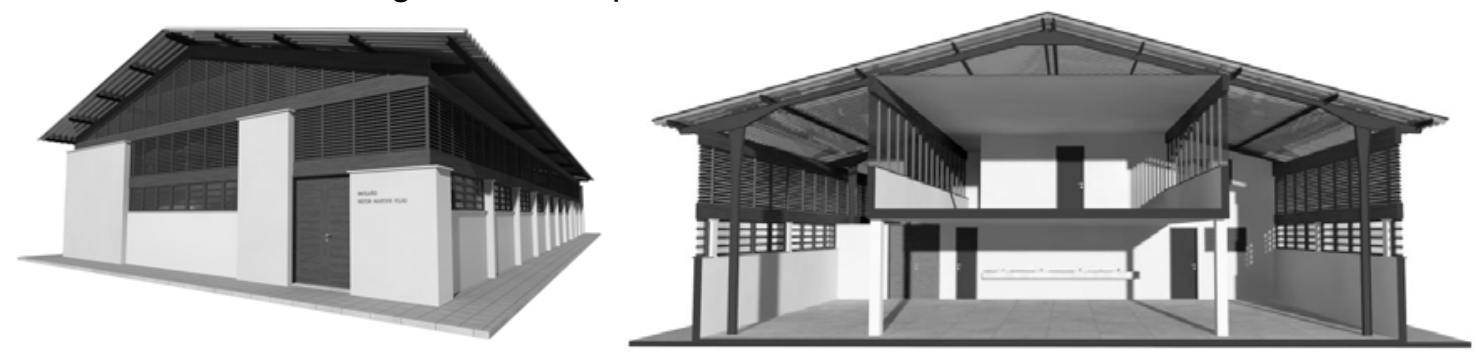

Fonte: Modelo desenvolvido na disciplina DAAC. Autora Karine Rabelo

Figura 5 - Perspectiva do Pavilhão Martins Filho.

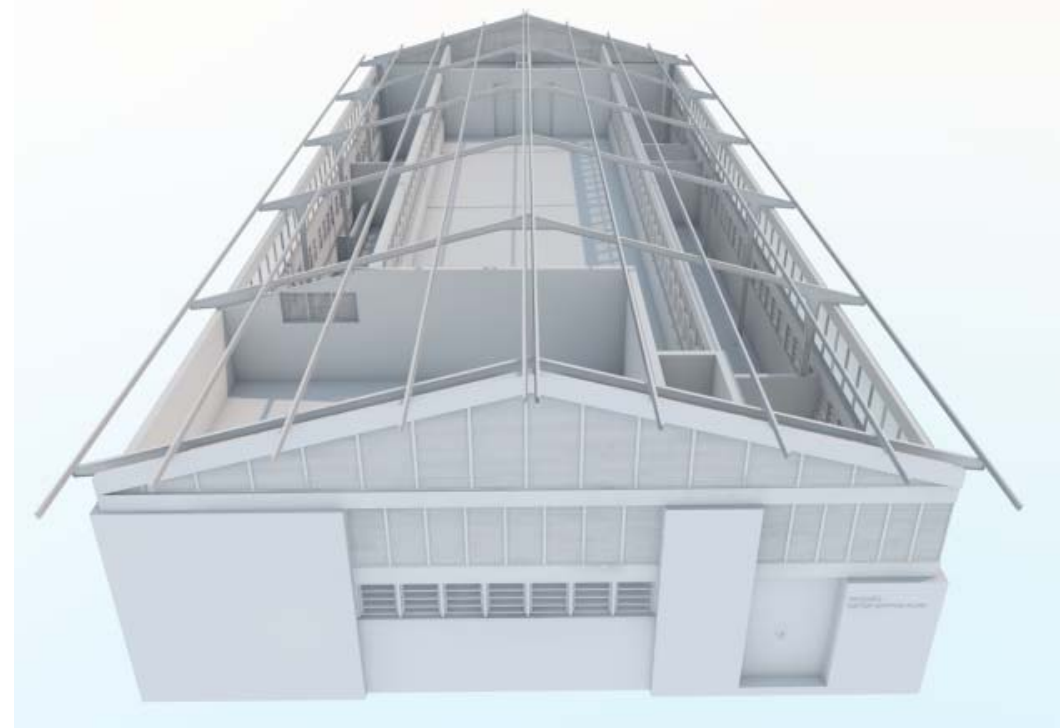

Fonte: Modelo desenvolvido na disciplina DAAC. Autora Bárbara Rodrigues 
Figura 6 - Perspectiva Interna do Pavilhão Martins Filho.

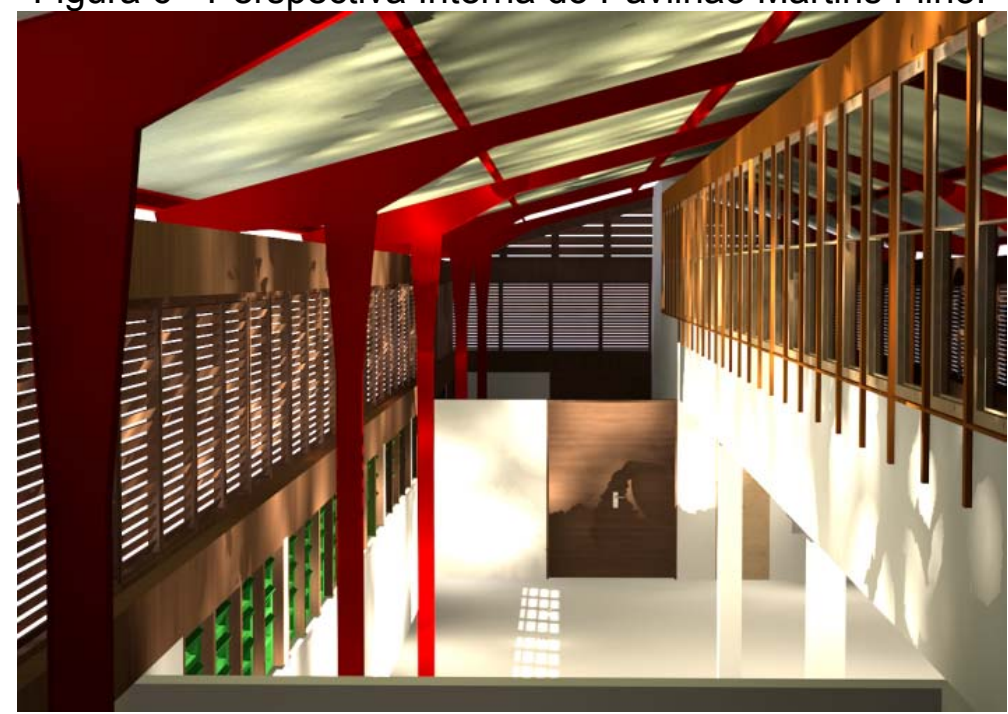

Fonte: Modelo desenvolvido na disciplina DAAC. Autora Bárbara Rodrigues

Pretende-se, ainda nesse semestre, iniciar a prototipação com o modelo do Pavilhão Martins Filho, para tanto será utilizada a impressora 3D Projet 160 (3D System).

Ademais, como parte das atividades da pesquisa "(Re)construção da Arquitetura Moderna em Fortaleza: memória e modelagem digital" está em processo de materialização alguns modelos tanto no âmbito do LoCAU e LED, como nas disciplinas de DAAC, como o Ginásio Paulo Sarasate do arquiteto Ícaro de Castro Melo, o Edifício Panorama Artesanal dos Arquitetos Fausto Nilo e Delberg Ponce de Leon e antigo Clube de Regatas da Barra do Ceará do arquiteto Ivan Brito, todos já documentados no Guia e publicados no site guiaarquiteturamodernafortaleza.arquitetura.ufc.br.

\section{CONCLUSÕES}

A documentação digital do acervo da arquitetura modernista (demolido e remanescente) de Fortaleza evidenciará os estudos realizados e em andamento no PPGAU+D-UFC (Programa de Pós-Graduação em Arquitetura e Urbanismo da Universidade Federal do Ceará), subsidiando as pesquisas dos mestrandos, possibilitando a divulgação dos seus resultados, suscitando o aprofundamento de alguns temas e abrindo fóruns de debates sobre a valorização e conservação do patrimônio moderno.

As novas tecnologias digitais devem ser incorporadas como aliadas no processo de documentação e preservação da arquitetura, sendo o BIM uma importante plataforma de parametrização e informação do patrimônio edificado, ao permitir possíveis encaminhamentos em relação à intervenção no edifício existente e consequentemente a sua preservação.

Enfim, a divulgação dos estudos sistemáticos sobre a arquitetura desse período ressalta a importância da documentação digital que, ao (re)construir virtualmente este legado, almeja ainda colaborar para a produção de conhecimento sobre a cidade e a arquitetura cearense, proporcionando às novas gerações, não somente de arquitetos, a consciência dessas referências modernas, garantindo, através da modelagem digital (futuro), a permanência dos valores da arquitetura moderna (pretérito). 


\section{AGRADECIMENTOS}

Ao CNPq, que concedeu auxílio financeiro para a pesquisa "(Re)construção da arquitetura moderna em Fortaleza: memória e modelagem digital" desde janeiro de 2015; à UFC, que custeia os bolsistas de extensão; à CAPES, que custeia bolsistas do Programa Jovens Talentos da Ciência e aos alunos da graduação envolvidos nas disciplinas de DAAC.

\section{REFERÊNCIAS}

AMORIM, Luiz Manuel do Eirado. Obituário arquitetônico. Pernambuco modernista. Recife: Editora UFPE, 2007.

AMORIM, A. L.; GROETELAARS, N. J.; LINS, E. A. Um Centro de Documentação do Patrimônio Arquitetônico. Fórum Patrimônio: Ambiente Construído e Patrimônio Sustentável (UFMG. Online), v. 02, p. 09, 2008, pp. 194-206.

ANDRADE, M. L. V. X.; RUSCHEL, R. C. Building Information Modelling (BIM). In: O processo de projeto em arquitetura: da teoria à prática. São Paulo: Oficina de Textos, 2011, pp. 421-442.

JUCÁ NETO, C. R.; NASCIMENTO, J. C.; FERNANDES, R. Notas sobre o Inventário da Arquitetura Moderna da Universidade Federal do Ceará. Cadernos PPG-AU/FAUFBA, v. i, Salvador, 2010, pp. 19-35.

JUCÁ NETO, C. R.; GONÇALVES, A.; BRASIL, A. C. Arquitetura Moderna do Campus do Benfica - Universidade Federal do Ceará. Fortaleza: Edições UFC, 2014.

LIMA, Fábio. Ferramentas Digitais na Conservação do Art Déco. In: ARQdoc. III Seminário internacional sobre documentação do patrimônio arquitetônica com o uso de tecnologias digitais, 2014, João Pessoa. ARQdoc - Anais do Evento. João Pessoa: Editora UFPB, 2014.

OLIVEIRA, Mario Mendonça de. A Documentação como Ferramenta de Preservação da Memória. Brasília: IPHAN / Programa Monumenta, 2008.

PAIVA, Ricardo Alexandre; DIOGENES, B. H. Um Moderno Convicto: Roberto Castelo. Revista Arquitetura e Urbanismo, v. 156, 2006, p. 57-62.

PAIVA, Ricardo Alexandre; DIOGENES, B. H. A contribuição de José Liberal de Castro à arquitetura no Ceará. Arquitextos (São Paulo), v. 1, p. 13.154, 2013.

SEGAWA, Hugo. Arquiteturas no Brasil 1900-1990. São Paulo: Editora da Universidade de São Paulo, 2002.

TOLENTINO, M. M. A.; FEITOSA, B. B. L. A utilização das tecnologias digitais na documentação do patrimônio arquitetônico. In: ARQdoc. III Seminário internacional sobre documentação do patrimônio arquitetônica com o uso de tecnologias digitais, 2014, João Pessoa. ARQdoc - Anais do Evento. João Pessoa: Editora UFPB, 2014. 